\title{
Intimate Partner Violence in Bangladesh: A Scoping Review
}

\author{
Jhantu Bakchi ${ }^{1 *}$, Satyajit Kundu², Subarna Ghosh ${ }^{3}$, Sumaiya Akter ${ }^{4}$ \\ 1. Department of Public Health, North South University, Dhaka, Bangladesh, \\ Email: jbakchi.nfs.pstu@gmail.com ORCID: https://orcid.org/0000-0001-5599-9884 (*Corresponding author). \\ 2.Department of Biochemistry and Food Analysis, Patuakhali Science and Technology University, Dumki, \\ Patuakhali-8602, Bangladesh, Email: satyajitnfs@gmail.com ORCID:https://orcid.org/0000-0001-9610-1479 \\ 3. Lecturer, Department of Public Health Nutrition, Primeasia University, Bangladesh, \\ Email: subarnaghosh.pstu@gmail.com \\ 4. Department of Food Microbiology, Patuakhali Science and Technology University, Dumki, Patuakhali-8602, \\ Bangladesh, Email: sumaiya.nst@gmail.com
}

\begin{abstract}
Introduction: Intimate Partner Violence (IPV) has unfavorable consequences for women as well as for newborn babies, which is very serious and preventable public health problem. It is believed to have an excessive occurrence in lives of women in South Asia. The objective of this study is to describe the prevalence, risk factors and consequences of IPV in Bangladesh. Methods: A scoping review was carried out based on the past 12 years of posted and gray literature about IPV in Bangladesh using Arksey and O'Malley's framework. Only the literature addressing abuses or violence in households or outside including physical, sexual or mental violence on the married woman in Bangladesh were taken into consideration for the study. Results: The overall prevalence of IPV in Bangladesh, the latest reviews of rates ranging from 15.5-82.7\%.Most of the IPV in Bangladesh was based totally on the experience of legally married women. The main risk factors of IPV in Bangladesh were women being younger, from lower socioeconomic reputation, from lower academic attainment and lower education of husband, dowry, child marriage, perceived disobedience of wives, family conflict, children had recently been ill, and incapability of to furnish sexual satisfaction. Maternal depressive symptoms, signs of stress, anxiety and constraint to the better health of young children are the main consequences of IPV in Bangladesh. Besides, IPV causes unwanted pregnancy, pregnancy loss in the form of miscarriage, induced abortion, or stillbirth and termination of pregnancy in Bangladesh. Conclusions: Woman's empowerment may reduce IPV and understanding attitudes towards IPV in cultural context could be crucial for developing interventions to reduce IPV and its consequences.
\end{abstract}

Keywords: Intimate Partner Violence, Health Consequence, Scoping Review, Bangladesh

Introduction: The occurrence of Intimate Partner Violence (IPV), a gross violation of human rights, is one of the most prevalent abuses throughout the world and common varieties of violence towards women such as physical, sexual, and emotional abuse and controlling behaviors via an intimate companion, low and middle-income nations have the greater incidence ${ }^{1}$. Intimate partner 
violence is really common in all fields like socioeconomic, spiritual, and cultural groups. Basically, women are reported as being victims of IPV. Intimate partner violence (IPV) is one of the most common forms of violence against women worldwide ${ }^{2}$.A large number of research work documents the prevalence, determinants, and consequences of men's violence against their wives and female partners. A review of population-based surveys from around the world identified that between $10 \%$ and $69 \%$ of women in various settings had been physically assaulted at least once by an intimate male partner ${ }^{3}$.

While domestic violence is a universal problem, it is a problem of extreme magnitude in less developed countries such as Bangladesh ${ }^{4}$. In Bangladesh, several studies identified a number of risk factors for IPV. For example, studies have identified that the risk of experiencing violence was significantly higher among younger women ${ }^{5,6}$, less educated women $^{7,8}$, women with less educated husbands ${ }^{7}$, women living in poor households ${ }^{7}$, and women who believed their husbands were justified in beating them in certain circumstances ${ }^{9}$.Evaluation of DHS information from 10 countries also reported that physical or sexual IPV ever stated by presently married women ranged from $17 \%$ in the Dominican Republic to $75 \%$ in Bangladesh in $2008^{10}$. A hospitalbased survey in Bangladesh indicated that $43 \%$ of females experience physical IPV in their lifetime, $35.5 \%$ of them experienced sexual IPV, and 32.5\% experienced each physical and sexualIPV ${ }^{11}$.An estimated three in every five ladies in Bangladesh experience violence along with physical or sexualviolence ${ }^{12}$. One of the most frequent forms of violence towards females globally is abuse through the husband or partner ${ }^{3}$.A study conducted in Bangladesh reported that more $94 \%$ of women had experienced physical, sexual, or psychological violence at some point in their marriage or intimate relationship ${ }^{4}$. Several consequences have been identified due to IPV, for example, there is a negative consequence of IPV on maternal, physical, and mental health ${ }^{13-15}$.This negative consequence of IPV on women may also affect their children's health directly and indirectly ${ }^{16,17}$.

Relevant information about IPV, the elements which generate the underlying causes where women experience IPV in these settings, with also to pick out the determinants of IPV and above all have to recognize its alarming incidence rates in Bangladesh as well as in South Asia. Bangladeshis are presently transitioning from low to middle-income nations rapidly but still, women are faced with undesirable violence from their partners, and thus IPV in Bangladesh is not only a human right issue but also a public health issue. Hence, this study is aimed to evaluate literature about IPV in Bangladesh to describe the prevalence, risk factors and consequences of IPV.

Methods: Arksey and O'Malley's (2005) five stages for scoping literature reviews were followed (see Figure 1).

\section{Stage 1: Defining the research question:} The research question was defined in collaboration with all researchers of the team with the identification of some 
abuse/form which may lead to IPV. Three major factors were considered which are known as potential forms of IPV in Bangladesh and which guided the review.

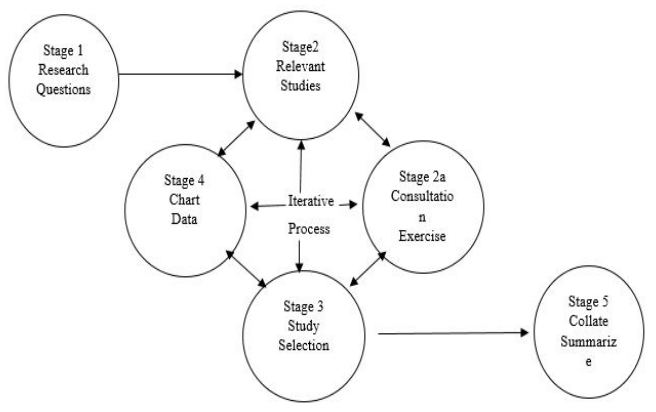

Figure 1: Arksey and O’Malley's framework stages for conducting a scoping review

\section{Operational definition-}

Domestic Violence- Any abusive, violent, coercive, forceful or threatening act or word inflicted by one member of a family or household on another can constitute domestic violence. It includes everything from saying unkind or demeaning words to grabbing a person's arm, to hitting, kicking, choking or even murdering.

Sexual harassment/abuse- is unwanted sexual activity, with perpetrators using force making threats or taking advantage of victims not able to give consent.

Gender-based violence-Gender-based violence is a phenomenon deeply rooted in gender inequality and continues to be one of the most notable human right violation within all societies. Gender-based violence is violence directed against a person because of their gender. Both men and women experience gender-based violence but the majority of victims are women and girls.
Stage 2: Identifying relevant studies: The inclusion and exclusion criteria and search strategy were developed and implemented with the input of the research team and focusing on the objective of the study. The inclusion and exclusion criteria are detailed below (see Table 1).

Our search strategy included: electronic databases, grey literature and reports on newspapers. The following databases were searched for spouse abuse/beating/ battering, home violence, intimate companion violence, spousal abuse, accomplice abuse, gender-based violence, and Bangladesh. Most of the articles were searched in PubMed, Research Gate, Embase and only open access articles were collected from them. The search was conducted on March 10, 2019, and updated up to 15 December 2019 including papers from 2007 (12 years prior to the initial search). Reference lists of included citations, key reports, organizational and other websites were hand-searched.

Stage 3: Study selection: Two researchers separately reviewed assigned titles and abstracts for relevance. Articles that were identified as relevant by either reviewer were considered for full-text review. Two researchers again separately examined full texts for their assigned papers for relevance; another two researchers were also appointed for resolving disagreements.

Stage 4: Charting the data: Data were abstracted by one reviewer and checked by another reviewer including: year of publication; purpose; participants/ population involved; type of nurse 
addressed; study design; research site(s); trends; outcomes and recommendations related to IPV.

Stage 5: Collating, summarizing and reporting the results: Stage 5 involved collating, summarizing and reporting results.

Results and Discussion: The search retrieved 70 citations, with 55 potential papers after dispelling duplications. Figure 2 presents a flowchart of literature retrieved levels of screening and included studies. This review included 22 distinct studies. Table 2 presents studies by study design/paper type. The findings are in the following sections, which center of attention on the occurrence of IPV, health consequences of IPV, danger elements for IPV, women's responses to IPV, health system responses to IPV, and elements affecting women's care-seeking behavior in Bangladesh.

Prevalence of IPV in Bangladesh: By using statistics from the chosen city and rural areas of Bangladesh the WHO Multicountry study revealed out women's fitness and home violence (lifetime IPV incidence over $50 \%$ ) \& this extremely excessive lifetime occurrence rate is steady ${ }^{18}$. Together, the literature suggested that an average of $15.5-48 \%$ of women in various places in Bangladesh have experienced IPV ${ }^{11,19-25}$. The highest prevalence rate used to be stated by women residing in rural areas in the peripheral zones backyard of Dhaka city (82.7\%), which included 77 villages in Bangladesh and the lowest prevalence rate was seen as $15.5 \%^{21,26}$. Some of the findings are not going to replicate the present rates of IPV in Bangladesh because of these incidence rates from the research were calculated 5-8 years ago. About $52-64 \%$ of women in a number of areas of Bangladesh experienced physical IPV and about the same for sexual IPV (11-65\%) which was stated by current community-based surveys ${ }^{23,24}$. The prevalence rate was also very high (43$63.8 \%$ ) in hospital-based studies where respondents described some bad consequences of IPV alongside physical and mental tortures ${ }^{11,27}$. Recently a study conducted in one of the slums of Dhaka city showed that IPV rate is the same as other communities which indicates that IPV may not vary on economic status $^{22}$.Besides, non-Muslim females and girls who watched mass media usually were less probable to be bodily abused through their husbands than Muslims and females who did not watch mass media at all ${ }^{19}$.The excessive occurrence of IPV experienced females in this study is steady with that mentioned in different research inBangladesh ${ }^{28-30}$.For females, in all levels of life, such as adolescents, pregnant women, older adults experiences of IPV had been documented, and the kinds of IPV experienced consisting of physical, sexual, emotional, and verbal abuse and a variety of controlling behavior in varying frequencies ${ }^{19,25-27}$. Additionally, sexual abuse was one of the predominant stated varieties of IPV in Bangladesh, with rates ranging from $6.2 \%$ to $65 \%$ but the majority of research mainly stated bodily violence as IPV $11,21,23,24,26,31$. A study also reported that three out of four $(75.6 \%)$ Bangladeshi women experience violence from husbands ${ }^{32}$. 
Different types of IPV in Bangladesh:

For females, in all levels of life, such as adolescents, pregnant women, older adults experiences of IPV had been documented, and the kinds of IPV experienced consisting of physical, sexual, emotional, and verbal abuse and a variety of controlling behavior in varying frequencies ${ }^{19,25-27}$. In addition, the partner's anger primarily based on jealousy, whenever, in search of health care for herself, it is the most frequent trouble being predicted to ask the partner's permission thus $84 \%$ of the female stated emotional violence through their intimate partner $^{24}$. Teasing (khota, tishara), demonstration of anger, verbal abuse (galigalaj), threat of abandonment or divorce and remarriage were the major kinds of emotional abuse. The most frequent form of physical IPV ever perpetrated used to be having slapped or thrown something at their partner, followed through having pushed or shoved their partner, hit their companion with a fist or something else, kicked, dragged, beaten, choked or burned their partner, and having threatened or used a gun or knife on their partner ${ }^{33}$.

Risk factors of IPV in Bangladesh: A woman's younger age, low socioeconomic reputation and low academic attainment, low education of husband, dowry, perceived disobedience of wives, family conflict and children had recently been ill are the wide variety of individual risk elements for IPV in Bangladesh which was recognized by many research ${ }^{22,23,26,27,34}$.In Bangladesh, dowry is associated with violence seems to be less frequent in contrast with different South Asian settings ${ }^{35,36}$.A study has found an association between early marriage and IPV and stated that the incidence rate used to be modestly in villages which are $(44.1 \%)$ with the reasonable occurrence of early child marriage (15-25\%), and was the best $(51.8 \%)$ in villages with the highest incidence of very early child marriage $(>25 \%)^{31}$. The lack of ability to work or to work properly, the incapability to furnish sexual satisfaction, and verbal conflict had been the major reason behind such abuse ${ }^{37}$.A study claimed that each physical and sexual IPV occurrence rate is greater amongst these respondents whose pregnancies were unintended and females belonging to the poorest category of relative family wealth ${ }^{19}$.Several studies showed that early reproductive women are more vulnerable to IPV who are in the range of 15-31 years ${ }^{22,25-27}$. Muslim women are at greater risk of IPV in Bangladesh $^{32}$.In addition, men who witnessed father-to-mother violence are more likely to perpetrate IPV, suggesting an intergenerational transmission of violence ${ }^{38}$.Moreover, ownership of jewellery/large household assets by woman, substance abuse by husband and his involvement in extramarital sex, and education of woman more than the husband increased the likelihood of IPV in Bangladesh $^{39}$. A randomized controlled trial study reported that women who were allocated to receive interactive messages about contraception were more likely to report physical IPV compared with the control group receiving usual care ${ }^{40}$.In Bangladesh, junior men are at heightened risks of perpetrating IPV and thus reducing the perpetration of IPV by them men is very critical ${ }^{41}$. 
Health outcomes and other consequences of IPV in Bangladesh: A current survey carried out in 2019 mentioned that one of every six female met the criteria for Major Depressive Episode (MDE) because of IPV; psychological factor was most common, accompanied through sexual and physical. Previous studies have revealed that the strong predictors of long-term bad intellectual health consequences amongst mothers are physical and sexual IPV, consisting of signs of stress, depression, and Anxiety ${ }^{18,42,43}$.Sexual violence turned into maternal depressive symptoms after 68 months of childbirth and has a stimulation on under-nutrition among under-5 children and thus different studies showed the IPV as a constraint to the better health of young children ${ }^{24,26}$. Accidents, small cut, physical pain, broken bone or tooth, abrasions, bruise-swelling, and burns are the kinds of physical fitness consequences of IPV in Bangladesh $^{21,22,27,44}$. While a variety of research had been carried out in rural settings and reported that physical accidents were greater than different consequences ofIPV ${ }^{21,22}$.

\section{IPV in Bangladesh during pregnancy} and it's consequences: Nearly $15.5-65 \%$ of females experienced IPV at some stage in pregnancy, ensuing in pregnancy and labor problems and different detrimental outcomes for themselves and their newborns, it is possible to know that previous researches were investigated IPV on the time of pregnant and lactating period $^{11,19,24-26,44}$. Another study indicated that IPV during pregnancy prohibited getting proper Antenatal Care (ANC) and the extreme physical IPV and low utilization of adequate ANC have an enormous association between them. The study also found that, due to the low use of medically trained providers for assistance with delivery, mothers experience physical IPV and sexual IPV ${ }^{19}$.There's another association between maternal physical IPV experiences and the low use of ANC which was found by data from a statewide survey in India ${ }^{45}$ and clinic-based research in developed settings ${ }^{46,47}$. In the preceding studies, it is displayed that there's a recognized association of IPV with lower ANC checkup and medically educated personnel who helped in delivery supply a crucial context for the extended rates of bad pregnancy effects and signs of gynecologic morbidity ${ }^{32,48,49}$. Besides, based on obtaining delivery care from a medical professional and visiting a professional ANC provider, it had been seen that women who have experienced each physical and sexual IPV are substantially less possibly to obtain or visit, which is shown in the findings of a study $^{19}$.

In another study, it was observed that over $25 \%$ of females looking for abortion care, experience IPV in the previous year; in turn, this was related to different achievable constraints to reproductive autonomy and reproductive healthoutcomes ${ }^{25}$. IPV can bring a reverse consequence on child health whose mother experienced IPV during pregnancy or lactating period. Maternal ride of any physical or sexual IPV used to be related to an elevated chance of stunting and underweight of their children ${ }^{26}$.Females who ever experienced physical and sexual IPV have a greater proportion of low birth weight ${ }^{11}$. However, other findings from 
Bangladesh also stated that the risk of illness is increasing in children aged 5 years and below whose mothers met the ARI and diarrhea criteria and who have experienced IPV in the preceding 12 months ${ }^{50}$.Women in Bangladesh experiencing violence from husbands were more likely to report both unwanted pregnancy and a pregnancy loss in the form of miscarriage, induced abortion, or stillbirth $^{32}$. Besides, physical IPV is significantly associated with the termination of pregnancy ${ }^{51}$.

\section{Acceptance of IPV and seeking} assistance: Besides, some studies mentioned that Bangladeshi women can also proceed with their life while staying in abusive relationships, in some instances for as long as many years even they do no longer expose IPV ${ }^{22,25}$. Another study found that whenever those physically abused women attempt to find help by disclosing their experience (only 21\%) and they get help according to their depicts (19\%). The possible reasons for no longer searching for help could be excessive stage of violence acceptance, worries about bringing an awful title to the family, lack of self-belief that this would be beneficial and shame/embarrassment/fear of getting blamed. Lack of facts concerning formal sources of assist hindered about $14 \%$ of the abused female from looking for help. Those who sought assistance did so ordinarily when they were unable to undergo violence anymore. Physically abused ladies most regularly are trying to find assistance from casual sources, such as relatives from their very own aspect and neighbors and very few females sought help from pretty formal sources such as nearby leaders/clubs and legal provider providers $^{22}$. The probability of disclosure and help-seeking is improving according to severe and prevalent physical abuse. The severity of violence regulating disclosure and help-seeking behavior $^{29,52,53}$ along with the age of the blamed women ${ }^{29,54}$, woman's incomeearning status ${ }^{54}$, and education ${ }^{55}$. Seeking help also depends on the presence of children in a violent relationship ${ }^{56}$. Due to lack of understanding of violence, many women in Bangladesh cannot seek help ${ }^{57}$.Violence against women in Bangladesh has both structural and systemic dimensions. The response of different women's groups and their strategies to counter violence is now an emerging trend in Bangladesh ${ }^{58}$. A study claimed that empowerment may be protective against IPV in the aggregate ${ }^{59}$.Moreover, understanding attitudes towards IPV in cultural context is important for developing interventions to reduce IPV and its consequences ${ }^{60}$.

Conclusions: Women being younger, from low socioeconomic reputation, from low academic attainment and low education of husband, dowry, child marriage, perceived disobedience of wives, family conflict, children had recently been ill, and incapability of to furnish sexual satisfaction were the wide variety of individual risk elements for IPV in Bangladesh. After all, IPV is no longer seen as a personal matter, it also helps to encouraged many women to search for outdoor services, if there seems to be an effective alternative in the understanding of IPV in Bangladesh. However, in moving forward, because of consisting of 
restrictive policies and practices that lower the reputation of women relative to men within the context of intimate relationships as well as their role in society, and many of the obstacles that stop female from in search of legal redress and recourse from IPV which is need to address.

Table 1: Inclusion and exclusion criteria

\begin{tabular}{|l|l|l|l|l|}
\hline & Populations & Exposure/Situation & Outcomes & Study design \\
\hline Inclusion & $\begin{array}{l}\text { Married } \\
\text { women, men, } \\
\text { adult girls and } \\
\text { boys }\end{array}$ & $\begin{array}{l}\text { Any abuses or violence } \\
\text { in household or } \\
\text { outside include sexual, } \\
\text { mental or physical } \\
\text { assault. }\end{array}$ & $\begin{array}{l}\text { All outcome } \\
\text { relevant to the } \\
\text { three sort of } \\
\text { violence }\end{array}$ & $\begin{array}{l}\text { All study designs } \\
\text { including published and } \\
\text { gray literature, primary } \\
\text { studies, newspaper } \\
\text { reports }\end{array}$ \\
\hline Exclusion & $\begin{array}{l}\text { teenager, } \\
\text { widow, } \\
\text { widower }\end{array}$ & $\begin{array}{l}\text { Unidentified rape case } \\
\text { or causalities between } \\
\text { two different } \\
\text { household }\end{array}$ & $\begin{array}{l}\text { conference abstract, } \\
\text { commentaries and } \\
\text { editorials }\end{array}$ \\
\hline
\end{tabular}

Table 2: Type of evidence included in the review $(\mathrm{n}=22)$

\begin{tabular}{|l|l|l|}
\hline Method & Description & References \\
\hline Quantitative (n=18; 81.8\%) & Cross sectional (n=6) & $24,39,23,22,44,51$ \\
\cline { 2 - 3 } & Hospital based $(\mathrm{n}=1)$ & 11 \\
\cline { 2 - 3 } & Secondary analysis $(\mathrm{n}=9)$ & $25,41,32,19,21,26,34,38,32$ \\
\cline { 2 - 3 } & Randomized control trial $(\mathrm{n}=1)$ & 40 \\
\cline { 2 - 3 } & Not specified $(\mathrm{n}=1)$ & 31 \\
\hline Qualitative $(\mathrm{n}=3 ; 13.6 \%)$ & Not specified $(\mathrm{n}=2)$ & 37,60 \\
\cline { 2 - 3 } & Case studies $(\mathrm{n}=1)$ & 59 \\
\hline Mixed method $(\mathrm{n}=1 ; 4.5 \%)$ & & 58 \\
\hline
\end{tabular}




\section{References}

1. WHO. Understanding and Addressing Violence against Women: Intimate Partner Violence. World Health Organization; 2012.

2. Devries KM, Kishor S, Johnson H, et al. Intimate partner violence during pregnancy: analysis of prevalence data from 19 countries. Reprod Health Matters. 2010;18(36):158-170.

3. Heise L, Ellsberg M, Gottemoeller M. Ending violence against women. Popul reports. 1999;27(4):1.

4. Hossain MA, Sumi NS, Haque ME, Bari W. Consequences of intimate partner violence against women on under-five child mortality in Bangladesh. $J$ Interpers Violence. 2014;29(8):1402-1417.

5. Ahmed MK, van Ginneken J, Razzaque A, Alam N. Violent deaths among women of reproductive age in rural Bangladesh. Soc Sci Med. 2004;59(2):311-319.

6. Johnson KB, Das MB. Spousal violence in Bangladesh as reported by men: prevalence and risk factors. $J$ Interpers Violence. 2009;24(6):977-995.

7. Koenig MA, Ahmed S, Hossain MB, Mozumder ABMKA. Women's status and domestic violence in rural Bangladesh: individual-and community-level effects. Demography. 2003;40(2):269-288.

8. Schuler SR, Hashemi SM, Riley AP, Akhter S. Credit programs, patriarchy and men's violence against women in rural Bangladesh. Soc Sci Med. 1996;43(12):1729-1742.

9. Kishor S, Johnson K. Profiling domestic violence: a multi-country study. 2004.

10. Hindin MJ, Kishor S, Ansara DL. Intimate partner violence among couples in 10 DHS countries: predictors and health outcomes. 2008.

11. Ferdos J, Rahman M. Maternal experience of intimate partner violence and low birth weight of children : A hospital-based study in Bangladesh. 2017:1-13.

12. Naved RT, Amin S. From Evidence to Policy: Addressing Gender-Based Violence against Women and Girls in Bangladesh. Dhaka, Bangladesh Int Cent Diarrhoeal
Dis Res Popul Counc. 2013.

13. Ribeiro WS, Andreoli SB, Ferri CP, Prince M, Mari JJ. Exposure to violence and mental health problems in low and middleincome countries: a literature review. Brazilian J Psychiatry. 2009;31:S49-S57.

14. Devries K, Watts C, Yoshihama M, et al. Violence against women is strongly associated with suicide attempts: evidence from the WHO multi-country study on women's health and domestic violence against women. Soc Sci Med. 2011;73(1):79-86.

15. Rose L, Alhusen $\mathrm{J}$, Bhandari $\mathrm{S}$, et al. Impact of intimate partner violence on pregnant women's mental health: Mental distress and mental strength. Issues Ment Health Nurs. 2010;31(2):103-111.

16. Yount KM, DiGirolamo AM, Ramakrishnan U. Impacts of domestic violence on child growth and nutrition: a conceptual review of the pathways of influence. Soc Sci Med. 2011;72(9):15341554.

17. Levendosky AA, Huth-Bocks AC, Shapiro DL, Semel MA. The impact of domestic violence on the maternal-child relationship and preschool-age children's functioning. $J$ Fam Psychol. 2003;17(3):275.

18. Ellsberg M, Jansen HAFM, Heise L, Watts $\mathrm{CH}$, Garcia-Moreno C. Intimate partner violence and women's physical and mental health in the WHO multi-country study on women's health and domestic violence: an observational study. Lancet. 2008;371(9619):1165-1172.

19. Rahman M, Nakamura K, Seino K, Kizuki M. Intimate partner violence and use of reproductive health services among married women: evidence from a national Bangladeshi sample. BMC Public Health. 2012;12(1):1. doi:10.1186/1471-2458-12913

20. Biswas RK, Rahman N, Kabir E, Raihan F. Women' $s$ opinion on the justification of physical spousal violence: A quantitative approach to model the most vulnerable households in Bangladesh. 2017:1-13.

21. Esie P, Osypuk TL, Schuler SR, Bates LM. SSM - Population Health Intimate partner 
violence and depression in rural Bangladesh: Accounting for violence severity in a high prevalence setting. SSM Popul Heal. 2019;7(December 2018):100368.

doi:10.1016/j.ssmph.2019.100368

22. Parvin K, Sultana N, Naved RT. Disclosure and help seeking behavior of women exposed to physical spousal violence in Dhaka slums. BMC Public Health. 2016:18. doi:10.1186/s12889-016-3060-7

23. Dalal K, Dahlström Ö, Timpka T. Interactions between micro fi nance programmes and non-economic empowerment of women associated with intimate partner violence in Bangladesh : a cross-sectional study. 2013:13-15. doi:10.1136/bmjopen-2013-002941

24. Kabir ZN, Nasreen H, Edhborg M. Intimate partner violence and its association with maternal depressive symptoms 68 months after childbirth in rural Bangladesh. 2014;1:1-7.

25. Pearson E, Andersen KL, Biswas K, Chowdhury R, Sherman SG, Decker MR. Intimate partner violence and constraints to reproductive autonomy and reproductive health among women seeking abortion services in Bangladesh. 2017;(October 2016):290-297. doi:10.1002/ijgo.12070

26. Rahman M, Poudel KC, Yasuoka J, Otsuka K, Yoshikawa K. Maternal Exposure to Intimate Partner Violence and the Risk of Undernutrition Among Children Younger Than 5 Years in Bangladesh. 2012;102(7):1336-1345. doi:10.2105/AJPH.2011.300396

27. Zaman H. Violence against women in bangladesh. Womens Stud Int Forum. 1999;22(1):37-48. doi:10.1016/S02775395(98)00093-4

28. Sambisa W, Angeles G, Lance PM, Naved RT, Curtis SL. Physical and sexual abuse of wives in urban Bangladesh: husbands' reports. Stud Fam Plann. 2010;41(3):165178.

29. Naved RT, Azim S, Bhuiya A, Persson LÅ. Physical violence by husbands: magnitude, disclosure and help-seeking behavior of women in Bangladesh. Soc Sci Med.
2006;62(12):2917-2929.

30. Garcia-Moreno C, Jansen HAFM, Ellsberg M, Heise L, Watts CH. Prevalence of intimate partner violence: findings from the WHO multi-country study on women's health and domestic violence. Lancet. 2006;368(9543):1260-1269.

31. Yount KM, Crandall A, Cheong YF, et al. Child marriage and intimate partner violence in rural Bangladesh: a longitudinal multilevel analysis. Demography. 2016;53(6):1821-1852.

32. Silverman JG, Gupta J, Decker MR, Kapur $\mathrm{N}$, Raj A. Intimate partner violence and unwanted pregnancy, miscarriage, induced abortion, and stillbirth among a national sample of Bangladeshi women. BJOG An Int J Obstet Gynaecol. 2007;114(10):12461252.

33. Sierra H, Cordova M, Chen CSJ, Rajadhyaksha M. Confocal imaging-guided laser ablation of basal cell carcinomas: An ex vivo study. $J$ Invest Dermatol. 2015;135(2):612-615.

doi:10.1038/jid.2014.371

34. Islam TM, Tareque MI, Tiedt AD, Hoque $\mathrm{N}$. The intergenerational transmission of intimate partner violence in Bangladesh. Glob Health Action. 2014;7(1):23591.

35. García-Moreno C, Hegarty K, d'Oliveira AFL, Koziol-McLain J, Colombini M, Feder G. The health-systems response to violence against women. Lancet. 2015;385(9977):1567-1579.

36. Jayasuriya V, Wijewardena K, Axemo P. Intimate partner violence against women in the capital province of Sri Lanka: prevalence, risk factors, and help seeking. Violence Against Women. 2011;17(8):1086-1102.

37. Naved RT, Blum LS, Chowdhury S, Khan R, Bilkis S, Koblinsky M. Violence against Women with Chronic Maternal Disabilities in Rural Bangladesh. 2012;30(2):181-192.

38. Islam MJ, Rahman M, Broidy L, et al. Assessing the link between witnessing inter-parental violence and the perpetration of intimate partner violence in Bangladesh. BMC Public Health. 2017;17(1):183.

39. Naved RT, Mamun M Al, Parvin K, et al. 
Magnitude and correlates of intimate partner violence against female garment workers from selected factories in Bangladesh. PLoS One. 2018;13(11):e0204725.

40. Reiss K, Andersen K, Pearson E, et al. Unintended consequences of mHealth interactive voice messages promoting contraceptive use after menstrual regulation in Bangladesh: intimate partner violence results from a randomized controlled trial. Glob Heal Sci Pract. 2019;7(3):386-403.

41. Yount KM, James-Hawkins L, Cheong YF, Naved RT. Men's perpetration of partner violence in Bangladesh: Community gender norms and violence in childhood. Psychol Men Masc. 2018;19(1):117.

42. Organization WH. Putting Women First: Ethical and Safety Recommendations for Research on Domestic Violence against Women. Geneva: World Health Organization; 2001.

43. Pallitto CC, Campbell JC, O'Campo P. Is intimate partner violence associated with unintended pregnancy? A review of the literature. Trauma, Violence, Abus. 2005;6(3):217-235.

44. Islam J, Broidy L, Baird K, Mazerolle P. Intimate partner violence around the time of pregnancy and postpartum depression: The experience of women of Bangladesh. 2017:1-24

45. Koski AD, Stephenson R, Koenig MR. Physical violence by partner during pregnancy and use of prenatal care in rural India. $J$ Health Popul Nutr. 2011;29(3):245.

46. Bailey BA, Daugherty RA. Intimate partner violence during pregnancy: incidence and associated health behaviors in a rural population. Matern Child Health J. 2007;11(5):495.

47. McFarlane J, Parker B, Soeken K, Bullock L. Assessing for abuse during pregnancy: severity and frequency of injuries and associated entry into prenatal care. Jama. 1992;267(23):3176-3178.

48. Stephenson R, Koenig MA, Ahmed S. Domestic violence and symptoms of gynecologic morbidity among women in
North India. Int Fam Plan Perspect. 2006:201-208.

49. Jasinski JL. Pregnancy and domestic violence: A review of the literature. Trauma, Violence, \& Abuse. TRAUMA, VIOLENCE, Abus. 2004;5(1):47-64.

50. Silverman JG, Decker MR, Gupta J, Kapur N, Raj A, Naved RT. Maternal Experiences of Intimate Partner Violence and Child Morbidity in Bangladesh: Evidence From a National Bangladeshi SampleShort title: Maternal IPV and Child Morbidity. JAMA Pediatr. 2009;163(8):700-705.

51. Rahman M. Intimate partner violence and termination of pregnancy: a cross-sectional study of married Bangladeshi women. Reprod Health. 2015;12(1):102.

52. Ansara DL, Hindin MJ. Formal and informal help-seeking associated with women's and men's experiences of intimate partner violence in Canada. Soc Sci Med. 2010;70(7):1011-1018.

53. Ellsberg MC, Winkvist A, Peña R, Stenlund H. Women's strategic responses to violence in Nicaragua. $J$ Epidemiol Community Heal. 2001;55(8):547-555.

54. Hyman I, Forte T, Du Mont J, Romans S, Cohen MM. Help-seeking behavior for intimate partner violence among racial minority women in Canada. Women's Heal issues. 2009;19(2):101-108.

55. Coker AL, Derrick C, Lumpkin JL, Aldrich TE, Oldendick R. Help-seeking for intimate partner violence and forced sex in South Carolina. Am J Prev Med. 2000;19(4):316-320.

56. Meyer S. Seeking help to protect the children?: The influence of children on women's decisions to seek help when experiencing intimate partner violence. $J$ Fam Violence. 2010;25(8):713-725.

57. Morrison KE, Luchok KJ, Richter DL, Parra-Medina D. Factors influencing helpseeking from informal networks among African American victims of intimate partner violence. $J$ Interpers Violence. 2006;21(11):1493-1511.

58. Zaman H. Violence against women in Bangladesh: issues and responses. In: Women's Studies International Forum. Vol 
22. Elsevier; 1999:37-48.

59. Schuler SR, Lenzi R, Badal SH, Bates LM. Women's empowerment as a protective factor against intimate partner violence in Bangladesh: a qualitative exploration of the process and limitations of its influence. Violence Against Women. 2017;23(9):1100-1121.

60. Schuler SR, Yount KM, Lenzi R. Justification of Wife Beating in Rural Bangladesh: A Qualitative Analysis of Gender Differences in Responses to Survey Questions. Violence Against Women. 2012;18(10):1177-1191. doi:10.1177/1077801212465152

Author contributions: $1^{\text {st }}$ author developed the concept and design of the paper; $2^{\text {nd }}, 3^{\text {rd }}$ and 4 th were equally involved in the literature search, review, compilation, manuscript writing and revision.

Conflicts of interests: The authors are declaring that they have no conflicts of interest. 